\title{
Design and Application of the Eccentric Modified Gears
}

\author{
Fan Suxiang ${ }^{1,2}$ \\ ${ }^{1}$ College of Engineering, China Agricultural University, \\ Beijing, 100083, China; \\ ${ }^{2}$ Mechanical College, North China University of Water \\ Resources and Electric Power, Zhengzhou, 450011,China \\ Liu Yingchao \\ BeijingVocational College of Agriculture, Beijing 102208, China.
}

\author{
Hou Shulin* \\ College of Engineering, China Agricultural University, \\ Beijing, 100083, China
}

\begin{abstract}
To ensure the variation of tooth backlash in allowable value required in common gears transmission, a new transmission mechanism was proposed in this paper to solve the problem of tooth backlash change, composed by an eccentric gear and an eccentric modified gear. The design principle of the eccentric gears was described in this paper. According to the involutes tooth profile generating principle, the tooth profile data was obtained. The eccentric modified gears were manufactured through powder metallurgy, and were successfully applied to the planetary transplanting mechanism, passing the field testing.
\end{abstract}

Key words-Eccentric modified gear , Modified gear,Backlash , Rice planetary transplanting mechanism

\section{INTRODUCTION}

Eccentric gear is used widely in the non-uniform speed transmission because of its simple structure and easy manufacture. Compared with oval and noncircular gear, eccentric gear backlash changes cyclically in high-speed performance, which will cause vibration, so it is generally used for inaccurate non-uniform transmission. Chen Yiqun and Yuan Zhaohe got the approximate transmission trajectory, ignoring the changes of eccentric gear backlash ${ }^{[1]}$. Guo LS pointed out that the pitch curve of the two eccentric gears in meshing was not always tangent, which can not be regarded as pure rolling ${ }^{[2]}$. Zhao Yun et al proved three important properties of the eccentric gear planetary drive, and applied modern design theory and methods to optimize the core of the working parts of the rice transplanter ${ }^{[5]}$. Eccentric gear planetary transplanting mechanism was first applied successfully in high-speed rice transplanter and is still in use now ${ }^{[6-7]}$. In order to eliminate backlash, in Japan the mechanism uses overlapping two-piece of gear and scroll spring which cause structure complicated.

In this paper a new transmission mechanism ${ }^{[8]}$ composed by an eccentric gear and an eccentric modified gear was designed to eliminate the backlash of the eccentric gear transmission. Unlike the general modified gear, the modification coefficient of the eccentric gear was always changing according to the backlash of the eccentric gear in one rotation cycle. In this paper, the mechanism theoretical analysis and the field experiment was carried out.

Supported by National High Technology Research and Development Program( 2012AA10A503 )Supported by the National Natural Science Fund Projects ( 50875244、51005214)

\section{THE TRANSMISSION PRINCIPLE OF ECCENTRIC GEAR AND AN ECCENTRIC MODIFIED GEAR}

As eccentric gear drive will have a backlash change, thus in the modification coefficient calculation of eccentric and the eccentric modified gear transmission, the eccentric gear drive backlash variation must first be developed.

Two same eccentric gears $I$ and $I I$ are engaged with the same teeth number and module, as shown in Fig.1. $O$ and $B$ are gear axle centers (rotation centers); $\mathrm{O}_{1}, \mathrm{O}_{2}$ are geometrical centers, respectively. In the initial position, the angle between rotation center line $O B$ and $\mathrm{X}$-axis is $\varphi_{0} . O O_{1}$ is in the line of $\mathrm{OB}$, and $\mathrm{BO}_{2}$ is in the extension line of $\mathrm{OB}$. When gear $I$ rotates $\varphi_{1}$ in a counter-clockwise direction, gear $I I$ rotates $\varphi_{2}$, and point A is the intersection of line $\mathrm{O}_{1} \mathrm{O}_{2}$ and line $O B$.

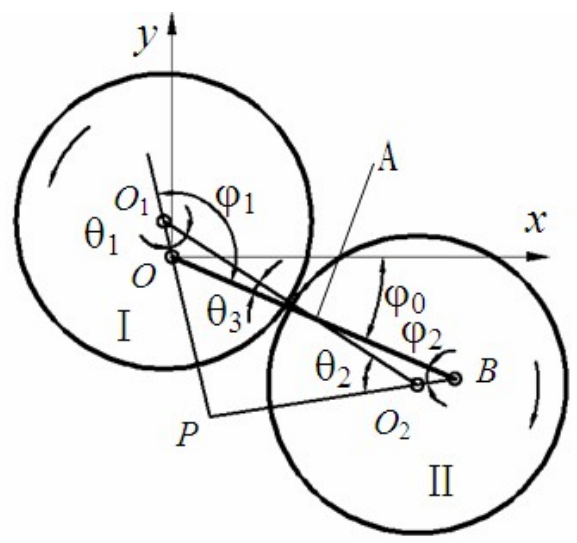

Fig.1 Sketch of eccentric gear-drive

According to eccentric gear transmission properties ${ }^{[3]}$, arbitrary geometric center distance of gear $I$ and $I I$ can be expressed as:

$$
l_{\mathrm{O}_{1} \mathrm{O}_{2}}=l_{\mathrm{AO}_{1}}+l_{\mathrm{AO}_{2}}=\frac{a\left(\left|\sin \varphi_{1}\right|+\left|\sin \varphi_{2}\right|\right)}{2\left|\sin \theta_{1}\right|}
$$

Eq. (1) shows that in the transmission process, the 
geometrical center distance of two eccentric gears changes with angular displacement $\varphi_{1}$, so the gear backlash is also changing.

At any time the eccentric gear drive can be seen as a two-center distance of standard cylindrical gears transmission whose center distance is $l_{\mathrm{O}_{1} \mathrm{O}_{2}}$. The rotation center of the two standard cylindrical gears are $O_{1}$ and $O_{2}$ respectively. As the geometric center distance is no longer always equal to the standard center distance, the backlash occurs between meshing tooth surface of two eccentric gears. The gear angular displacement $\varphi_{1}$ is divided into $\mathrm{N}$ portions within the range of $0 \sim 360^{\circ}$, each corresponding gear section pitch. At each point the gear is angular modified, and the gear tooth thickness is changed, so that the backlash is zero.

The actual pressure angle can be calculated according to the relationship between the center distance and the pressure angle as follows ${ }^{[9]}$.

$$
\alpha=\arccos \left(\frac{a_{0} \cos \alpha_{0}}{l_{\mathrm{O}_{1} \mathrm{O}_{2}}}\right)
$$

Where $a_{0}$ is standard center distance, $a_{0}=2 R . \alpha_{0}$ and $\alpha$ is standard gear pressure angle and working pressure angle respectively.

Suppose $\mathrm{C}$ is the backlash between two eccentric gears, in order to compensate for the backlash, the two eccentric gears are modified to meet the non-backlash meshing conditions. Non-backlash meshing equations can be written as ${ }^{[10]}$.

where $\operatorname{inv} \alpha=\tan \alpha-\alpha$

$$
\operatorname{inv} \alpha=\frac{2\left(x_{1}+x_{2}\right) \tan \alpha_{0}}{z_{1}+z_{2}}+i n v \alpha_{0}
$$

$$
\operatorname{inv} \alpha_{0}=\tan \alpha_{0}-\alpha_{0}
$$

$z_{1}$ and $z_{2}$ are number of the two gears teeth, and $z_{1}=z_{2}=Z$

$X_{1}$ and $x_{2}$ are the modification coefficient of the two gears.

As the eccentric gear is easy to manufacture, the eccentric gear is I modified only, and gear II remains unchanged. So we can get:

$$
x_{1}=0 \quad x_{2}=x
$$

The modification coefficient of gear $I / \mathrm{can}$ be obtained as

$$
x=z\left(i n v \alpha-i n v \alpha_{0}\right) / \tan \alpha_{0}
$$

So the backlash between the two eccentric gears can be expressed as:

$$
C=2 m x \tan \alpha
$$

Fig.2 shows the relationship of backlash $\mathrm{C}$, angular displacement $\varphi_{1}$ and eccentricity $\varepsilon$ of eccentric gears. As can be seen, the backlash fluctuates twice in one cycle, and the fluctuation increases with the eccentricity increasing, which far exceeds allowed range.

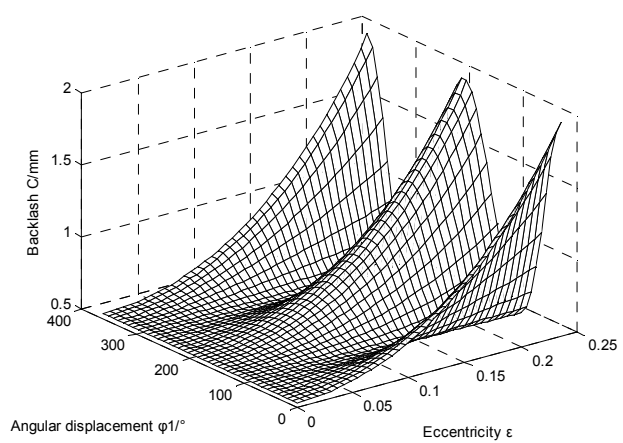

Fig.2 Relationship of backlash C, angular displacement $\varphi_{1}$ and eccentricity $\mathcal{E}$ of eccentric gears.

In order to avoid the modification coefficient is too large to reduce the coincidence degree and reduce the structural size, the rotation center distance will be reduced to meet the strength of gear and avoid undercut. Axis distance between eccentric gear and eccentric modified gear can be expressed as
[11].

$$
a=d R
$$

Where $d$ is relative rotation center distance of the two gears, $d=2+\frac{\varepsilon^{2}}{2}+\frac{35 \varepsilon^{4}}{32}$.

Fig. 3 shows the relationship of modification coefficient $x$, angular displacement $\varphi_{1}$ and eccentricity $\varepsilon$ of eccentric gears. The modification coefficient can be positive or negative. If the eccentricity is zero, then the modification coefficient is zero, without the need for modification. If the eccentricity is not zero, then the modification coefficient will fluctuate periodically, and the fluctuation increases with the eccentricity increases, and all the fluctuation curves are consistent. Furthermore, the modification coefficient reaches the maximum when $\varphi_{1}$ is $0^{\circ}$ or $180^{\circ}$, and the minimum appears when the angle $\varphi$ slightly less than $90^{\circ}$ or slightly greater than $270^{\circ}$.

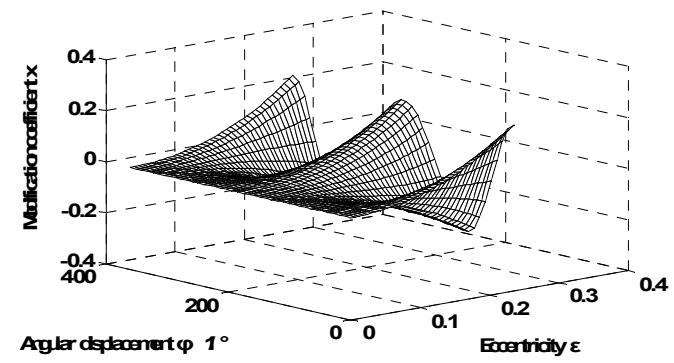

Fig.3 Relationship of modification coefficient $x$, angular displacement $\varphi_{1}$ and eccentricity $\varepsilon$ of eccentric gears 


\section{DESIGN OF ECCENTRIC MODIFIED GEAR}

In manufacturing the rack cutter pitch line is tangent and pure rolling down the pitch curve of eccentric gear, and plus modification perpendicular to rack cutter. So the eccentric modified gear is enveloped with the same as ellipse or non-circular gear.

Assumes that the rack cutter roll about the fixed gear blank without sliding on the pitch of eccentric modified gear. Fig.4 shows the relationship of tooth rack and gear blank.

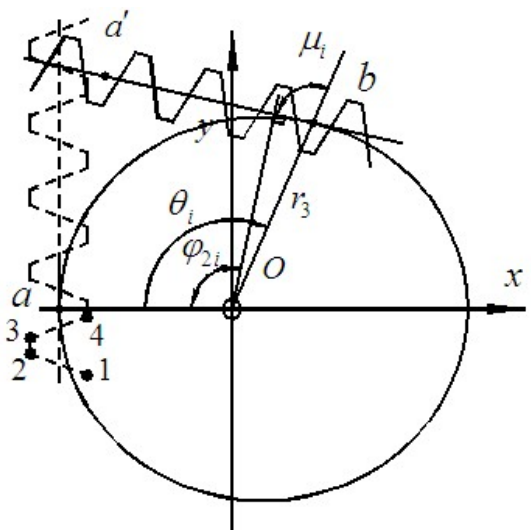

Fig.4 Relationship of tooth rack and gear blank

The pitch curve of the eccentric gear can be expressed by the following equation:

$$
r_{2}=\sqrt{R^{2}-e^{2} \sin ^{2} \varphi_{2}}+e \cos \varphi_{2}
$$

So the pitch curve of the eccentric modified gear can be expressed by the following equation:

$$
r_{3}=\sqrt{R^{2}-e^{2} \sin ^{2} \varphi_{2}}+e \cos \varphi_{2}+m x
$$

Assumes the pitch of the rack cutter and the eccentric gear are tangent at point $a$ in the initial position. When the pitch rack cutter rolls along the pitch gear to the polar angle $\varphi_{2 i}$ and tangent at point $b$, the angle between the pitch rack cutter and the radius vector is expressed as follows ${ }^{[12]}$.

$$
\mu_{i}=\arctan \frac{r_{3}\left(\varphi_{2 i}\right)}{\left(\frac{d r_{3}}{d \varphi_{2}}\right) \varphi_{2 i}}
$$

When point $a$ moved to the point $\mathrm{b}$, the $a b$ arc length $\mathrm{S}$ along the pitch gear is equal to the distance between point $a^{\prime}$ and $b$. The arc length can be expressed as follows:

$$
S=l_{a^{\prime} b}=\int_{0}^{\varphi_{2 i}} \sqrt{r_{3}^{2}+\left(d r_{3} / d \varphi_{2}\right)^{2}} d \varphi_{2}
$$

The rotated angle of rack cutter can be expressed as follows:

$$
\theta_{i}=\varphi_{2 i}+\mu_{i}-\frac{\pi}{2}
$$

When the rack cutter rotates one cycle, according to the formula $(8) \sim(10)$, the pitch curve of the gear blank $I /$ can be enveloped.

Based on the gear blank pitch enveloped by the straight pitch of the rack cutter, the involute gear tooth profile is enveloped by rack cutter teeth. The tool rack cutter is composed of some teeth and each tooth can be represented by four vertices. Fig. 4 shows the relationship of tooth rack and gear blank. The first tooth is composed of four vertices $1,2,3$, 4 , and the other teeth can be obtained by coordinate translation of the first tooth. When the gear blank angular displacement corresponding to the arc length is larger than a pitch or integer multiple of pitch, the rack cutter translates coordinate vector $y$ forward integer multiple pitch, to ensure every time sufficient rack teeth envelope gear. In the rack coordinate system the mathematical model of the rack cutter is represented as follows in matrix form.

$$
\begin{aligned}
& x_{0}=1.25 m[1,-1,-1,1] \\
& y_{0}=\left[-\frac{3 \pi m}{4}-l_{m},-\frac{3 \pi m}{4}+l_{m},\right. \\
& \left.-\frac{\pi m}{4}-l_{m},-\frac{\pi m}{4}+l_{m}\right]+n \pi m
\end{aligned}
$$

Where $l_{m}=1.25 m \tan \alpha$, and $\mathrm{n}$ is the teeth number of the rack cutter.

Turn the rack cutter to tangent direction of pitch gear blank, the mathematical model is represented as follows:

$$
\left\{\begin{array}{l}
x_{1}=x_{0} \cos (\mu-\pi / 2) \\
-\left(y_{0}-S+n \pi m\right) \sin (\mu-\pi / 2) \\
y_{1}=x_{0} \sin (\mu-\pi / 2) \\
-\left(y_{0}-S+n \pi m\right) \cos (\mu-\pi / 2)
\end{array}\right.
$$

Put the rack cutter tangent to the pitch gear blank, pure rolling position, and then offset $m x$ displacement. The mathematical model of the rack cutter can represented as follows:

$$
\left\{\begin{array}{l}
x_{3}=\left(x_{1}+r_{2}+m x\right) \cos \varphi_{2}-y_{1} \sin \varphi_{2} \\
y_{3}=\left(x_{1}+r_{2}+m x\right) \sin \varphi_{2}+y_{1} \cos \varphi_{2}
\end{array}\right.
$$

With the angle $\varphi_{2}$ constant changing, the rack cutter envelopes eccentric modified gear tooth profile in one circle, as shown in fig. 5 .

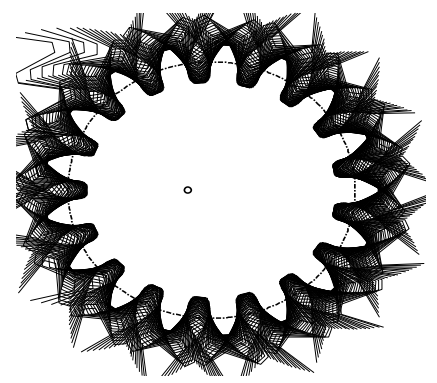

Fig.5 Tooth profile envelopment 


\section{DESIGN EXAMPLES AND EXPERIMENTS}

According to the tooth profile generation method, the eccentric modified gear tooth profile calculation software is designed in Matlab environment.

The software is composed of some modules, such as interface displays, undercutting discrimination, gear parameters calculation, tooth profile envelope, intersection calculation, feature points sorted and data output. Take the eccentric modified gear in the planetary transplanting mechanism for example to verify the correctness of eccentric modified gear design. The known eccentric gear tooth number is $Z=17$, module is $m=2.5 \mathrm{~mm}$, and eccentricity is $e=3.5 \mathrm{~mm}$. The axle center distance between the eccentric gear and conjugated gear is as follows:

$$
a=d R=42.8(\mathrm{~mm})
$$

The gear tooth profile generated is shown in Fig.6. Fig.6 shows Tooth profile of eccentric gear and eccentric modified gear.

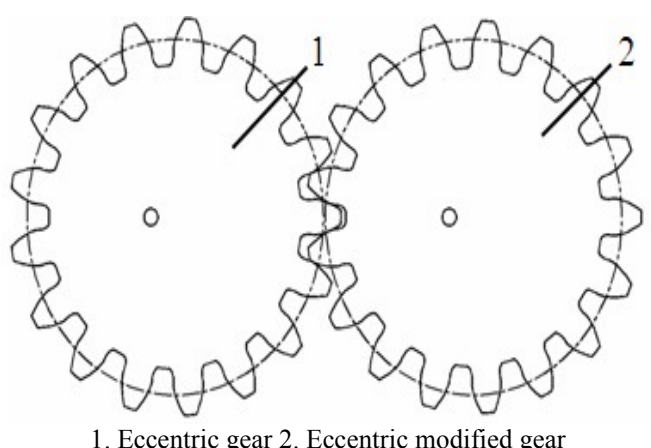

Fig. 6 Tooth profile of eccentric gear and eccentric modified gear

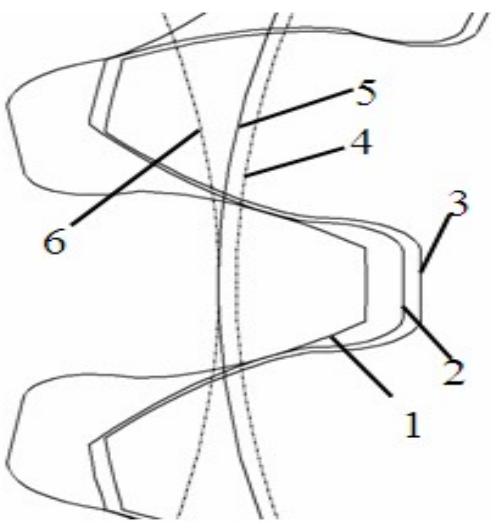

1. Eccentric gear tooth profile

2.Conjugated eccentric modified gear tooth profile

3. Conjugated eccentric gear tooth profile

4.Pitch of conjugated eccentric gear tooth profile

5. Pitch of conjugated eccentric modified gear tooth profile

6. Pitch of eccentric modified gear tooth profile

Fig.7 Comparison of enlarged diagram of gear meshing

Fig. 7 shows the comparison of enlarged diagram of gear meshing. There is meshing backlash in eccentric gear 1 and 3, while no backlash in eccentric gear 1 and eccentric modified gear 2 .In the initial position the two eccentric gear pitch is separated, while pitches of the eccentric gear and eccentric modified gear is tangent. Throughout the meshing process, the pitches of the two eccentric gear are sometimes separated or intersected, and only tangent at certain points, which proves that the hypothesis of two pitches are tangent and pure rolling is not established, so there is backlash in the meshing eccentric gears. While the pitches of the eccentric gear and eccentric modified gear are always tangent and pure rolling without backlash.

The eccentric modified gear is applied to the plantery transplanting mechanism of rice tranlplanter, as shown in Figure 8 . The transplanting mechanism consists of three eccentric gears $1,3,5$ and two eccentric gears 2, 4, 10 planetary frame (gear box) and two planting arm 7, 9, in which 1,5 are the planet gears, gear 3 is the sun gear, and gear2 and 4 are the middle gears.



Fig.8 Diagram of transplanting mechanism with the eccentric gears

Use the meshing of the eccentric gear and eccentric modified gear to achieve non-uniform transmission, choose the appropriate eccentricity and center distance from the to realize the required transmission ratio and the rotation angle relation and obtain "kidney" static track 8 of working requirement. The mechanism is suitable for different size of the seedling transplanting requirements, too.

The eccentric modified gear planetary transplanting mechanism is applied to the 6 lines wide-narrow row riding type transplanter, and the field test is carried out. Test prototype id as shown in fig. 9. 




Fig.9 Experimental prototype

Fig.10 shows the comparison of two types transplanting mechanisms. Figure (a) is gear box photo of Japan transplanting mechanism with eccentric gears, which has a total of 9 eccentric gears with same eccentricity, the planetary gears and the middle gears consists of two sheet gear-superposition and dislocation installation Two positioning pins are respectively fixed on the two eccentric sheet gears and scroll-spring makes two gears mesh no-backlash. Figure (b) is gear box photo of transplanting mechanism with eccentric modified gear, which consists of 3 eccentric gears and 2 eccentric gears. The mechanism is simplified greatly.
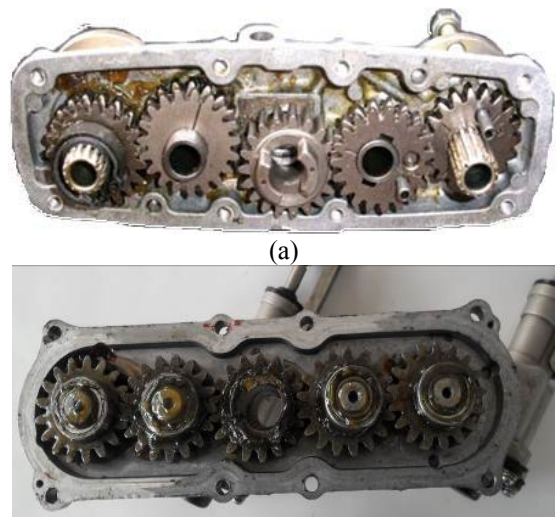

(b)

$\begin{array}{ll}\text { (a) Japan transplanting mechanism with eccentric gears } & \text { (b) Japan }\end{array}$ transplanting mechanism with eccentric modified gears

Fig. 10 comparison of transplanting mechanism

The field experiment is carried in Heilongjiang Jiansanjiang Farm. The test area is 0.7 hectares, the feet depth is $170 \mathrm{~mm}$, the average height of the seedlings with the $3-4$ leaf age is $50 \mathrm{~mm}$. the seedlings is raised in seedling tray with the width of $300 \mathrm{~mm}$, in which the soil thickness is 19 to $21 \mathrm{~mm}$ and the soil moisture content is $48 \%$. Field experimental results are shown in Table 1.

TAB.1 FIELD EXPERIMENTAL RESULTS

\begin{tabular}{|c|c|c|l|}
\hline Test item & $\begin{array}{c}\text { Technical } \\
\text { requireme } \\
\text { nts }\end{array}$ & $\begin{array}{c}\text { Test } \\
\text { results } \\
\text { (Average) }\end{array}$ & $\begin{array}{l}\text { Individual } \\
\text { decision }\end{array}$ \\
\hline $\begin{array}{c}\text { Relative } \\
\text { uniformity } \%\end{array}$ & $\geq 85$ & 93 & Qualified \\
\hline
\end{tabular}

\begin{tabular}{|c|c|c|c|}
\hline $\begin{array}{c}\text { Planting depth } \\
/ \mathrm{mm}\end{array}$ & $10 \sim 35$ & 20 & Qualified \\
\hline $\begin{array}{c}\text { Row spacing } \\
/ \mathrm{mm}\end{array}$ & $\begin{array}{c}\text { Wide } \\
\text { row:400 }\end{array}$ & 402 & \multirow{2}{*}{ Qualified } \\
\cline { 2 - 3 } & $\begin{array}{c}\text { Narrow } \\
\text { row: } 200\end{array}$ & 198 & \\
\hline $\begin{array}{c}\text { Miss panting } \\
\text { rate/\% }\end{array}$ & $\leq 5$ & 1.3 & Qualified \\
\hline $\begin{array}{c}\text { Seedling injury } \\
\text { rate/\% }\end{array}$ & $\leq 4$ & 2.0 & Qualified \\
\hline $\begin{array}{c}\text { Floating } \\
\text { seedling rate } \\
/ \%\end{array}$ & $\leq 3$ & 1.4 & Qualified \\
\hline $\begin{array}{c}\text { Productivity } \\
/ \mathrm{hm}^{2} \cdot \mathrm{h}^{-1}\end{array}$ & $0.3 \sim 0.5$ & 0.38 & Qualified \\
\hline
\end{tabular}

From the experimental results, the prototype operation quality is good, and the main test performance indicators can meet the design requirements.

\section{CONCLUSION}

(1)The variable modification method of the eccentric gear according to the backlash variation is feasible. The gear mechanism with the eccentric modified gear can eliminate the backlash in meshing.

(2)The value of modification depends on the backlash, and the backlash depends on center distance of the coefficient of variation

(3)Rice transplanter experimental report shows that work performance quality meet the state standards.

\section{REFERENCES}

[1] Chen Yiqun, Yuan Zhaohe. Parameter optimization of transplanting mechanism with planetary eccentric gears[J]. Transactions of the Chinese Society for Agricultural Machinery ,1992, 23(1): 28-33.

[2] Guo L S, Zhang W J. Kinematic analysis of a rice trans-planting mechanism with eccentric planetary gear trains $[\mathrm{J}]$. Mechanism and Machine Theory, 2001,36 (11 - 12): 1175-1188.

[3] Zhao Yun, Sun Liang, Yu Gaohong. Properties and applications of the eccentric-gear drive[J]. Chinese Journal of Mechanical Engineering, 2011, 24(2):323-331.

[4] Zhao Yun agricultural and mechanical analysis and synthesis [M]. Beijing: Mechanical Industry Press, 2008

[5] Zhao Yun Zhao Xiong,et al. Modern design theory and method of rice transplanter[J]. Transactions of the Chinese Society for Agricultural Machinery,2011,42(3) : 65-68.

[6] Taki K. Basic research of key components of rice transplanter for early rice planting $[\mathrm{J}]$. Japanese Society of Agricultural Machinery, 1998, 60(4):13-22.

[7] Konoshi T, et al. Development of high performance rice transplanter[J]. Japanese Society of Agricultural Machinery, 1989, 51(6): 89-95.

[8] Zhejiang Sci-Tech University. Eccentric modified gear transmission mechanism: China, 200910098664.5[P].2009-10-21.

[9] Sun Huan, Chen Zuomo. Mechanical principles [M]. Beijing: Higher Education Press, 1996.

[10] Guo Keqiang. Involute modified gears transmission [M]. Beijing: Higher Education Press, 1985.

[11] Li Fusheng. Non-circular gear and special gear transmission [M]. Beijing: Mechanical Industry Press, 1983

[12] Chen Xingshen, Chen Weihuan. Lectures on differential geometry (the Second Edition) [M]. Beijing: Peking University Press, 2003. 